\title{
ESTADO PRISIONAL E POLÍTICA CARCERÁRIA NO PARÁ
}

\author{
PENAL STATE AND PRISON SYSTEM IN THE STATE OF PARÁ
}

\section{Luis Fernando Cardoso e Cardoso ${ }^{1}$ Roberto Magno Reis Netto ${ }^{2}$ Herick Wendell Antônio José Gomes ${ }^{3}$}

\begin{abstract}
1 Doutor em Antropologia Social pela Universidade Federal de Santa Catarina. Professor da Faculdade de Ciências Sociais do Instituto de Filosofia e Ciências Humanas da Universidade Federal do Pará.

E-mail: luiscardt@gmail.com Orcid: http://orcid.org/0000-0002-9240-5544 Lattes: http://lattes.cnpq.br/9240601863315295

2 Doutorando em Geografia (UFPA). Mestre em Segurança Pública (UFPA). Especialista em Atividade de Inteligência e Gestão do Conhecimento (ESMAC/PA), Docência no Ensino Superior (UGF/DF) e Direito Processual Civil (UGF/DF). Professor e Pesquisador (membro do Érgane - Instituto Científico da Amazônia, do Laboratório de Pesquisa e Geografia da Violência e do Crime - LAB-GEOVCRIM/UEPA - e do Grupo de Métodos de Diagnóstico em Segurança Pública- PPGSP/UFPA).

E-mail: bob_reis_ufpa@yahoo.com.br Orcid: http://orcid.org/0000-0002-5076-6149 Lattes: http://lattes.cnpq.br/5368010317556530
\end{abstract}

3 Mestre em Segurança Pública (UFPA). Especialista em Atividade de Inteligência e Gestão do Conhecimento (ESMAC/PA). Especialista em Defesa Social e Cidadania (IESP). Tenente-Coronel da Polícia Militar do Estado do Pará.

E-mail: herickwendel@gmail.com Orcid: http://orcid.org/0000-0001-8256-9281 Lattes: http://lattes.cnpq.br/5907661456622087

RESUMO: Nas últimas décadas do século XX, o capitalismo se reconfigurou, tanto o capital, como as relações de classes e de trabalho, o que causou um aumento substancial do desemprego, pobreza e exclusão social, aumentando substancialmente a criminalidade. Nesta perspectiva, este estudo buscou investigar como o Estado prisional foi adotado como política de segurança pública no Brasil. Com base na análise de dados oficiais do Sistema Penal, verifica-se a destinação considerável de recursos financeiros ao encarceramento seletivo da população, em detrimento de ações previdenciárias e assistenciais, evidenciando-se que o Estado assumiu o encarceramento como uma das políticas de controle social.

Palavras-chave: Capitalismo. Criminalidade. Estado prisional. Políticas de controle social.

ABSTRACT: In the late decades of the 20th century, capitalism went through a new period. There was a reconfiguration of the capital and the relations between social classes and work, which caused a substantial increase in job losses, poverty, and social exclusion, which led to the substantial rising of crimes. The given study, in this perspective, sought to investigate how the State's correction was embraced as a policy of public safety in Brazil. Based on the data analysis of the System of Corrections, it is verifiable that considerable funds are sent towards selective imprisonment, to the detriment of actions towards prevention and assistance, providing evidence that the State took imprisonment as a policy of social control.

Keywords: Capitalism. Crime. State's correction. Social control policies.

Sumário: Introdução - 1 O Estado Prisional - 2 Elementos Definidores de um Estado Prisional no Brasil 3 Elementos Definidores de um Estado Prisional na Política Penitenciária do Estado do Pará - Considerações Finais - Referências

\section{INTRODUÇÃO}

Nas últimas décadas, o capitalismo transformou as relações de trabalho, precarizando-as de tal maneira que isso gerou altos índices de desemprego, pobreza e marginalização nos países ricos e pobres, numa tentativa de liberar as forças vivas do mercado, além de submeter os mais pobres ao estímulo de uma competição socioeconômica. Esse momento, denominado de neoliberalismo, assenta-se num projeto aberto, que levou a várias e novas configurações, nas quais o Estado se mantém com base numa conjunção de forças políticas, econômicas e sociais, que se caracteriza pela liberação dos mercados, privatização de unidades 
indústrias e de serviços, desregulamentação das relações de trabalho, assim também, como a flexibilização salarial e redução das políticas públicas de inclusão social.

Mesmo que se tenha uma pluralidade de configurações neoliberais, há um núcleo que articula o Estado, o mercado e a cidadania. Esse centro aparelha o Estado para impor a marca do mercado sobre a cidadania e os direitos constitucionais e isso leva a uma constatação, são decisões político e culturais que determinam a estatística carcerária, e não o nível ou a evolução da criminalidade. É nesse contexto específico que os pobres passaram a serem representados como um sério problema para os Estados nacionais, que precisam controlá-los de forma efetiva e dura, por conta da diminuição de políticas sociais, que assumiam a função de controle no Estado de bem-estar social.

Neste sentido, este estudo tem como principal objetivo investigar como a nova política de controle social no Estado neoliberal define-se como Estado prisional. Pois este modelo de controle social baseia-se no discurso político-jurídico que criminaliza e segrega os pobres e difunde a intolerância com eles, usando o encarceramento para neutralizar e estocar fisicamente as frações excedentes da classe operária, notadamente os membros despossuídos dos grupos estigmatizados que insistem em se manter em rebeliões aberta contra o ambiente social.

Para melhor análise a pesquisa foi divida em três partes: a primeira procurou investigar como o Estado prisional substituiu os benefícios previdenciários e assistenciais construídos pelo Estado de bemestar social; a segunda, buscou entender como os elementos definidores de um estado prisional se instalou no Brasil e; por fim, busca avaliar os elementos definidores de um estado prisional na política penitenciária do estado do Pará

\section{O ESTADO PRISIONAL}

O Estado prisional substitui os benefícios previdenciários e assistenciais construídos pelo Estado de bem-estar social (Welfare State) (MORAIS; WERMUTH, 2013), que vigorou até a década de 1980 do século XX nos países europeus e da América do Norte, pela prisão das classes excluídas. O principal argumento dos defensores do Estado prisional para desmontar a política do welfare state é o fato de que ela teria ocasionado a estagnação das economias ocidentais, uma vez que a "redistribuição de recursos produzida pelo welfare state teria acontecido em detrimento do setor privado e do público; do capital e do trabalho; da renda mais alta e da renda mais baixa; e dos setores produtivos da população (jovens) e dos improdutivos (velhos)" (SEIBEL, 2005, p. 95).

$\mathrm{Na}$ América Latina, não houve uma política de controle social associada a políticas direcionadas às camadas com menor poder aquisitivo. Azevedo (2005, p. 222) esclarece que "diferentemente dos países centrais do capitalismo, Brasil e Argentina [...] nunca contaram com mecanismos em condições de substituir as funções exercidas pelo sistema penal’. O principal mecanismo de controle das camadas pobres da população sempre foi o sistema de justiça. Essa perspectiva, no entanto, tem sido explorada intensamente desde a década de 1980, em decorrência da incapacidade do Estado para exercer outras formas de controle social.

O Estado tem assim apostado no encarceramento em massa como forma de gerir a miséria. E os jovens pobres, negros e trabalhadores precarizados ou desempregados são seus principais alvos. Dessa forma, "o cárcere funciona como mero depósito de grupos populacionais considerados 'naturalmente' perigosos e de risco para os quais não resta outro remédio senão aplicar e reforçar técnicas de controle cada vez mais capilares e totalizadoras" (KILDUFF, 2010, p. 245). O aumento da população carcerária brasileira, portanto, "deve-se mais a uma política de repressão e de criminalização à pobreza, do que a uma política capaz de diminuir as ocorrências criminais" (MONTEIRO; CARDOSO, 2013, p. 101, grifo do autor).

Para Wacquant (2015), a forma de controle social no Estado prisional apresenta as seguintes características: fim do tratamento complacente com o crime; inflação legislativa, acompanhada da invenção de tecnologias e burocracias de controle jurídico do crime e dos criminosos; expansão de um discurso alarmista, com a ajuda da mídia; preocupação com a eficácia no combate ao crime, com forte valorização da vítima e estigmatização dos criminosos; descrença na possibilidade de reabilitação do criminoso; preocupação com 
os custos do encarceramento e; endurecimento da atuação policial e judiciária, com processos simplificados e rápidos. Contudo, em termos práticos, eis o que essa política representava:

[...] a resposta burocrática das elites políticas às mutações do assalariamento (passagem para os serviços e a polarização das ocupações, flexibilização e intensificação do trabalho, individualização dos contratos de emprego, descontinuidade e dispersão dos trajetos profissionais) e seus efeitos devastadores nos escalões inferiores da estrutura social e espacial (WACQUANT, 2015, p. 30).

Segundo Morais e Wermuth (2013, p. 168), o real propósito dessa postura estatal consistiria em “[...] isolar e neutralizar a população que de nada serve à configuração atual de sociedade". Ou, simplesmente, conforme informa Pastana (2012, p. 126), “[...] conter o refugo social produzido pelo recente contexto liberal'. Simbolicamente, essa forma de controle reafirma a força do Estado diante da população mais pobre e, também, representa um novo consenso sobre os fundamentos dos investimentos públicos em justiça social e penal.

De fato, apesar de não ser intencionalmente produzido (WACQUANT, 2015), esse modelo representava o resultado de forças convergentes no campo político para enfraquecer, ainda mais, o Estado de bem-estar social, substituindo as políticas previdenciárias por políticas prisionais severas (KILDUFF, 2010; MORAIS; WERMUTH, 2013; PASTANA, 2012; SEIBEL, 2005). Neste momento, portanto, apresenta-se como de fundamental importância ampliar as análises sobre as políticas penais adotadas pelos países de orientação neoliberal, que se alinham ao que a teoria sociológica contemporânea passou a denominar de Estado punitivo.

É nesse universo que este empreendimento busca evidenciar que o Estado do Pará adota o Estado prisional como forma de gestão das desigualdades sociais em relação às classes sociais perigosas: jovens socialmente excluídos, notadamente negros e pobres. Para tanto, será feito um cruzamento de dados nacionais - do Departamento Penitenciário Nacional (DEPEN), vinculado ao Ministério da Justiça (MJ) - e regionais - da Superintendência do Sistema Penitenciário do Estado do Pará (SUSIPE). Serão ainda usados dados de natureza previdenciária e demográfica, de âmbito também nacional e regional, para mostrar as consequências do Estado neoliberal num dos principais estados da Amazônia brasileira.

\section{ELEMENTOS DEFINIDORES DE UM ESTADO PRISIONAL NO BRASIL}

A constatação da existência do Estado prisional no Brasil talvez gere controvérsias, principalmente pelo fato de o país ter passado por um período de ditadura civil-militar, durante o qual o aprisionamento e a tortura eram medidas comuns (AZEVEDO, 2005; FIGUEIREDO, 2015), sendo natural, portanto, que os índices de aprisionados àquela época fossem altos. No entanto, deve-se ressaltar que esses dados se referiam a um período de forte repressão político-ideológica e não de crime, diferentemente do que se constata hoje.

Outro elemento que talvez obrigue a confirmar a impropriedade do Estado prisional no Brasil é a inexistência do Estado do bem-estar social (Di Pietro, 2001; SALLA; BALLESTEROS, 2008). Quando essa política de Estado vigorou na América do Norte ou na Europa, o Brasil estava em plena ditadura militar. Somente depois do ano de 2000, houve políticas assistenciais defendidas por uma ala da política brasileira, as quais, embora tenham representado um significativo avanço em relação ao combate à miséria, não foram capazes de enfrentar a situação criminológica no país.

Se as políticas de bem-estar social não chegam ao Brasil ou se aqui chegaram de maneira reduzida e atrasada, por outro lado, a rigidez das políticas de segurança pública sempre foi evidente e concreta. Isso se manifesta no treinamento e na formação de agentes brasileiros no período da ditadura civil-militar (FIGUEIREDO, 2005), assim como na integração política a certos eixos de combate ao crime e de guerra às drogas (RODRIGUES, 2004).

Incrustou-se na cultura sociopolítica brasileira uma postura de combate ao crime semelhante ao 
modelo da Lei e Ordem (a chamada política “tolerância zero”), adotado em Nova York, nos Estados Unidos da América, caracterizado pelo uso da máquina estatal para fins repressivos, num forte adensamento de um modelo penalista de tratamento jurídico-político do crime (SOUZA, 2015).

Como resultado, constatou-se uma forte seletividade na justiça criminal brasileira, acompanhada do desrespeito aos direitos humanos e do crescimento da sensação de impunidade e de insegurança, alimentados, em certa medida, pela mídia (SOUZA, 2015). Tais elementos aproximam-se dos quadros analíticos definidores de um Estado prisional (WACQUANT, 2015). Mas os dados do sistema prisional brasileiro são capazes de confirmar as hipóteses do pesquisador francês? Examinar tais questões é o que se fará a seguir. Conforme dados oficiais do DEPEN do Ministério da Justiça (BRASIL, 2014), entre os anos de 1990 e 2014, houve um recrudescimento do número de encarcerados, da ordem de 575\%, o que importou em 607.731 presos, número apurado à época do levantamento.

Gráfico 1 - Evolução do quantitativo de pessoas privadas de liberdade (mil pessoas/ano), no âmbito carcerário nacional, no ano de 2014

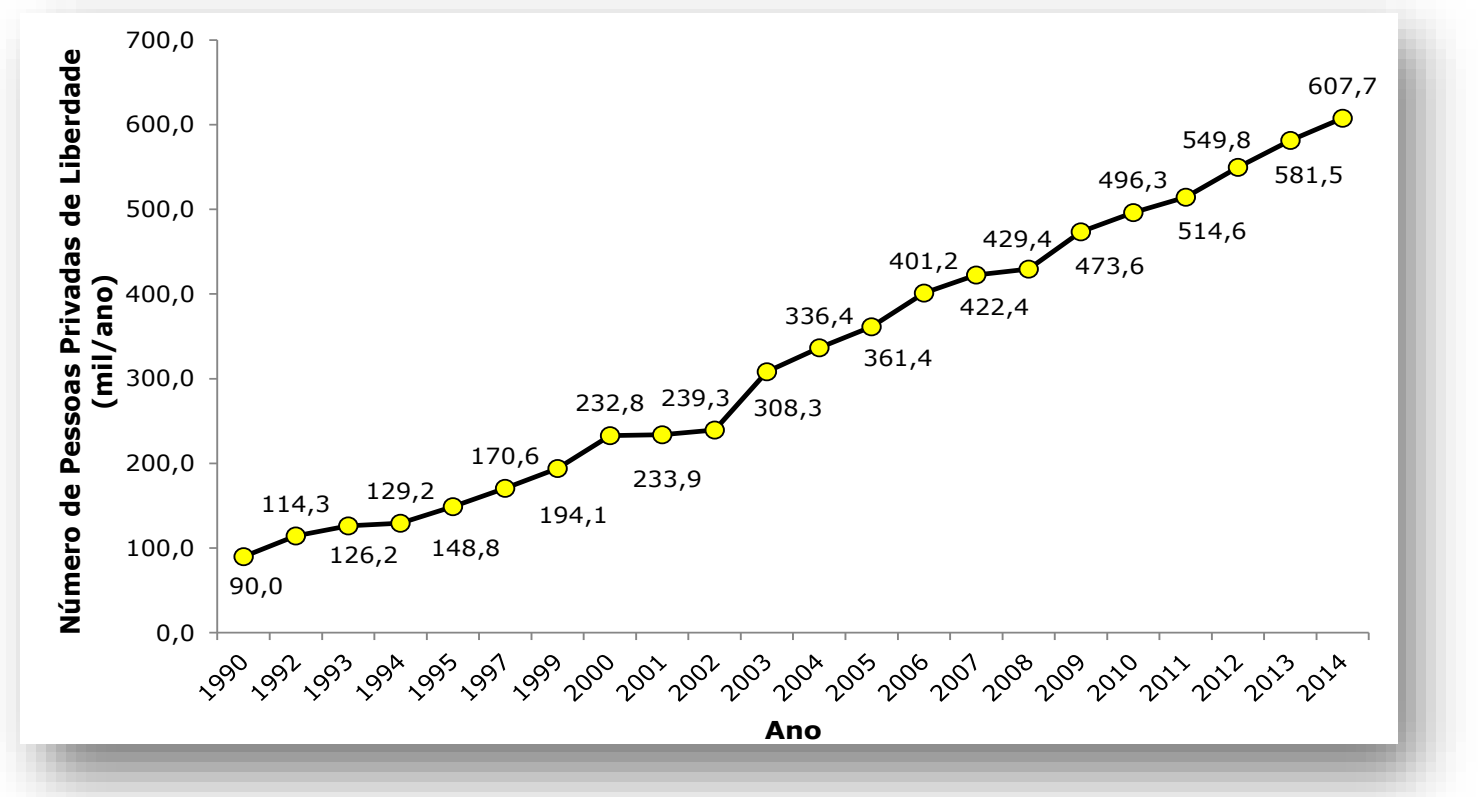

Fonte: Brasil, 2014, p. 15.

Sublinha-se que, comparativamente, o crescimento populacional e o crescimento populacional prisional possuem desníveis significativos. Enquanto a população brasileira, conforme dados do Instituto Brasileiro de Geografia e Estatística (IBGE, 2016), entre os anos de 2000 e 2014, cresceu 16,90\%, a população carcerária nacional cresceu, aproximadamente, 161,05\% no mesmo período. Constata-se, assim, que o aumento da população prisional é expressivamente maior que o aumento da população brasileira nesse período.

Ainda conforme os mesmos dados prisionais (BRASIL, 2014), o Brasil, em 2014, era o quarto país do mundo em população prisional, ficando atrás apenas dos EUA, da China e da Rússia. Já em termos de população prisional por 100 mil habitantes, o país é o terceiro colocado do ranking, com 300 presos para cada 100 mil habitantes, atrás apenas dos EUA (698 presos/100mil habitantes) e da Rússia (468 presos/100mil habitantes). O país ainda figurava como o quinto país com o maior número de presos sem julgamento, presos provisórios, do mundo (BRASIL, 2014).

O número de encarcerados reflete as características do Estado prisional, principalmente pela seletividade na faixa etária - 75\% de jovens com idades entre 18 e 29 anos (Brasil, 2014) - e pela seletividade racial - 67\% dos presos são de cor negra, menos de 31\% são brancos e 2\% são amarelos e indígenas.

O estudo do DEPEN (BRASIL, 2014) confirma a desproporção no número de negros encarcerados, 
67\% dos presos, enquanto a população negra no país é de 51\%. Enquanto há mais negros nas prisões comparativamente à população nacional, o contrário verifica-se com os brancos: $31 \%$ dos encarcerados são brancos, enquanto a população branca nacional corresponde a 48\%. Se há mais negros que a média nacional nas prisões, por outro lado, há menos brancos.

Gráfico 2 - Aprisionados, segundo o critério de raça autodeclarada, em comparação com o quantitativo da população nacional, no Brasil, no ano de 2014

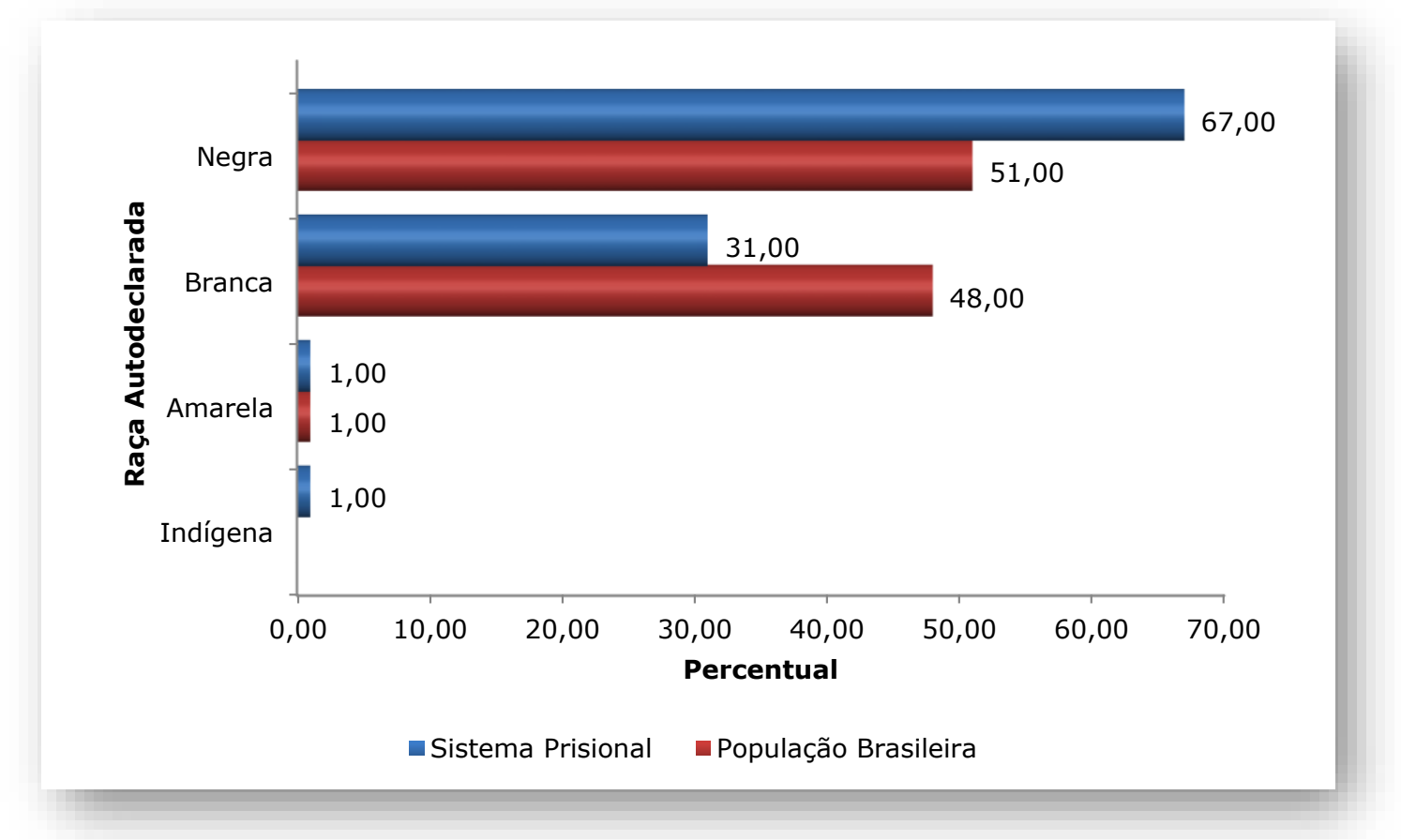

Fonte: Brasil, 2014, p. 50.

Quanto ao grau de escolaridade, 6\% dos presos são analfabetos, 9\% são alfabetizados sem cursos regulares, $53 \%$ têm o nível fundamental incompleto, 12\%, o nível fundamental completo, 11\%, o nível médio incompleto, 7\%, o nível médio completo, 1\%, o nível superior incompleto e 1\%, o nível superior completo. Deduz-se desses dados que o contingente de presos corresponde justamente à parcela menos favorecida da população nacional, sem possibilidades de enquadramento na atual sistemática do mercado (WACQUANT, 2015). E, embora esses elementos já denunciem a efetiva adoção, pelo Brasil, de uma seletividade ínsita no modelo de Estado prisional, é necessário ir além.

Entre 2000 e 2014, a quantidade anual de benefícios concedidos pela Previdência Social teve um crescimento de 176,7\%. Isso correspondeu, em 2014, à concessão de 4.886 .734 de benefícios a contribuintes do Regime de Previdência e de somente 343.669 benefícios assistenciais, excluídos os Encargos Previdenci-

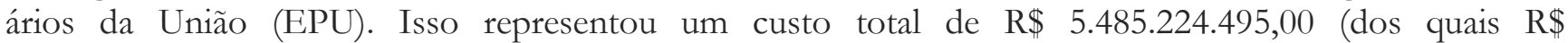
5.235.465.186,00 foram gastos com previdência e R\$248.766.109,00, com assistência - excluídos os EPU), relativo somente aos novos benefícios concedidos em 2014 (BRASIL, 2016).

No mesmo período, a população carcerária nacional, por sua vez, apresentou um aumento de aproximadamente $261 \%$, superior ao percentual de crescimento dos benefícios assistenciais concedidos naquele ano (159,2\%). Outrossim, havia 374,9 mil presos, cifra também superior à quantidade de benefícios assistenciais concedidos (343,6 mil aproximadamente). Supondo-se que cada preso, à época, custasse algo em torno de um salário mínimo ao governo federal ( $\mathrm{R} \$ 724,00$ em 2014), o custo mensal de sustento do sistema prisional corresponderia a $\mathrm{R} \$ 439.997 .224,00$. Ou seja, quase o dobro do gasto nacional em novos benefícios de assistência social ao longo do mesmo ano (BRASIL, 2014, 2016). 
Essa constatação demonstra a clara adoção de um modelo de Estado prisional no Brasil. E essa conclusão reforça-se mais ainda, se analisada conjuntamente com outros fenômenos sociais, como o agravamento dos mecanismos de punição criminal (como o observado com o advento da Lei no 11.343/06 - lei antidrogas e da Lei $n^{\circ}$ 12.850/12 - a lei de organizações criminosas), o advento de novos entendimentos judiciais mais rigorosos e menos ligados à humanização da justiça, a maciça atuação midiática na construção de uma imagem de insegurança, voltada para a eleição de políticos com típicos discursos baseados na criminologia da lei e ordem, e, finalmente, o crescimento de um debate sobre a privatização de presídios no Brasil (SILVA, 2016).

A política modelada pelo Estado prisional já pode ser sentida, inclusive, nos estados amazônicos, onde os índices de pobreza e os conflitos sociais são marcantes, pela própria dinâmica privatista típica da região Norte, bem como pelos baixos índices de investimento social, em comparação com o restante do país.

\section{ELEMENTOS DEFINIDORES DE UM ESTADO PRISIONAL NA POLÍTICA PENITENCIÁRIA DO ESTADO DO PARÁ}

O Estado do Pará, componente da região Norte, é um membro da federação brasileira que tem 144 municípios. Conforme o IBGE (2013b), para o ano de 2018, projetou-se uma população de 8.602.865 pessoas. A renda domiciliar per capita, apurada no ano de 2015, é de $\mathrm{R} \$ 672,00$, menos que um salário mínimo (IBGE, 2015 e 2019).Os dados da SUSIPE evidenciam que, em maio de 2016, o Estado do Pará tinha uma população carcerária absoluta de 14.789 presos (dos quais 14.374 se encontravam sob a responsabilidade da SUSIPE, ao passo que os demais, um total de 415, se encontravam nas carceragens dos variados órgãos policiais). Isso colocava o Estado do Pará na $14 .^{a}$ posição no ranking nacional, em termos de população carcerária absoluta no país. Na prática, o número de presos aumentou 1.182\% entre os anos de 1995 e 2016 (SUSIPE, 2016).

Gráfico 3 - Evolução do quantitativo de pessoas privadas de liberdade (mil pessoas/ano), no âmbito carcerário paraense, em comparação com o número de vagas disponíveis, em maio de 2016

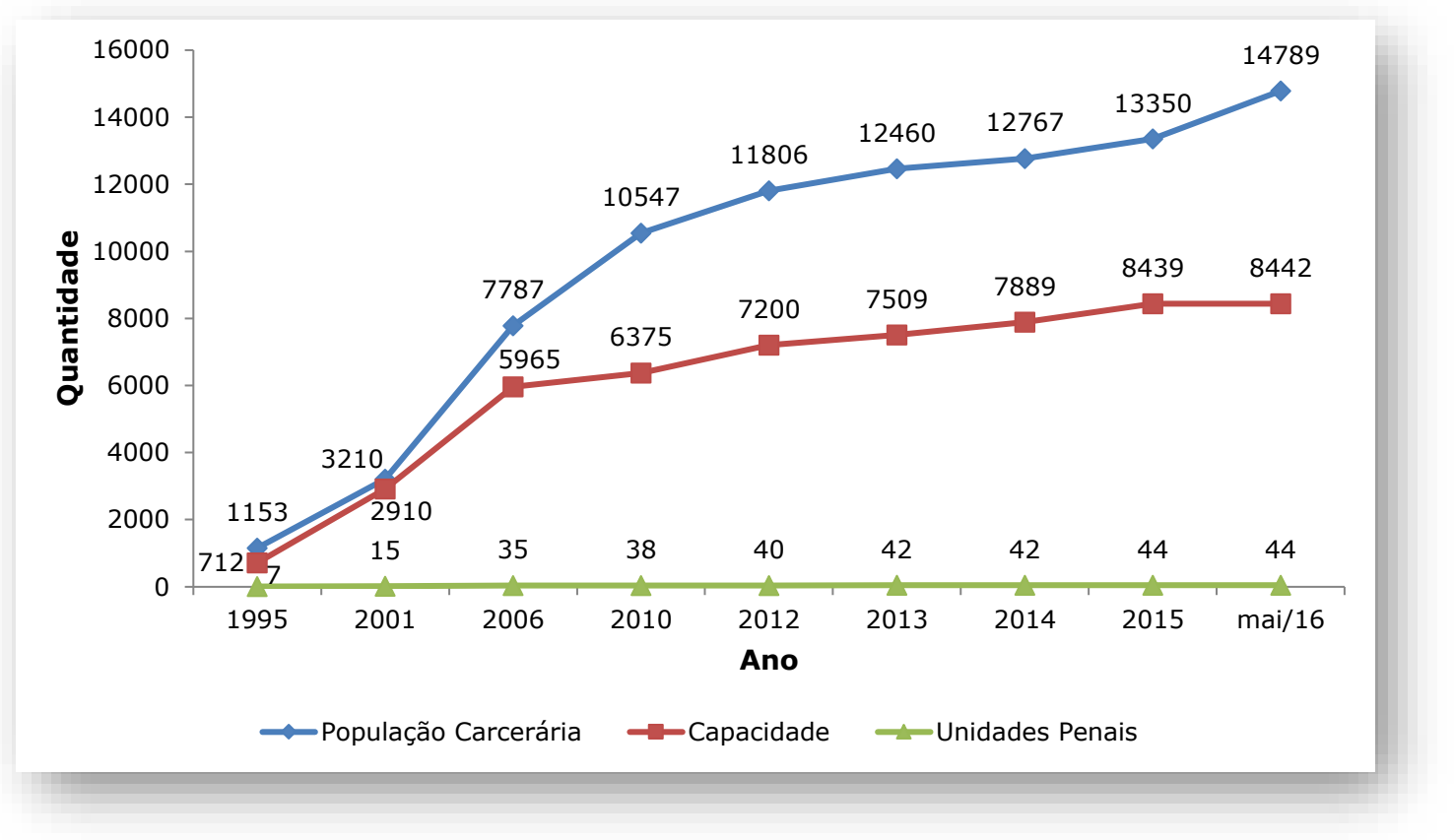

Fonte: SUSIPE, 2016. 
Comparando-se o aumento populacional ao de encarcerados, entre os anos de 2001 e 2016, constatase que a população paraense cresceu à taxa de 30,45\%, enquanto o número de aprisionados cresceu 460,71\%. Isso mostra que os encarcerados cresceram 15,13 vezes mais do que a população do Estado do Pará (IBGE, 2016; SUSIPE, 2016). No universo total de crimes imputados a presos homens, constata-se que cerca de 33,97\% correspondem a ilícitos contra o patrimônio, ao passo que 17,64\% se referem ao tráfico de drogas. Com relação às mulheres, os crimes de tráfico de drogas representam 64,5\% (SUSIPE, 2016), o que demonstra que o comércio ilegal, possivelmente, tem-se apresentado como uma forte alternativa econômica.

Com relação à cor, $69,5 \%$ da população paraense declararam-se parda, 7,2\%, preta, 21,8\%, branca e 1,5\%, não declararam. Assim, conforme critérios utilizados pelo IBGE (2013a), constata-se que 76,7\% da população paraense podem ser enquadrados na categoria "negros". Por outro lado, adotando-se o mesmo parâmetro, constata-se que $83 \%$ da população prisional paraense são compostos de pessoas negras (sendo $65 \%$ pardos e $18 \%$ negros), valor $6,3 \%$ superior ao da população em geral. Por sua vez, a quantidade de presos da cor branca é de 14,11\% (ou seja, 7,69\% menor em relação à população em geral), representando as demais raças o percentual de $2,89 \%$ dos presos.

Gráfico 4 - Percentual de presos, conforme o critério de raça autodeclarada, no Estado do Pará, em maio de 2016.

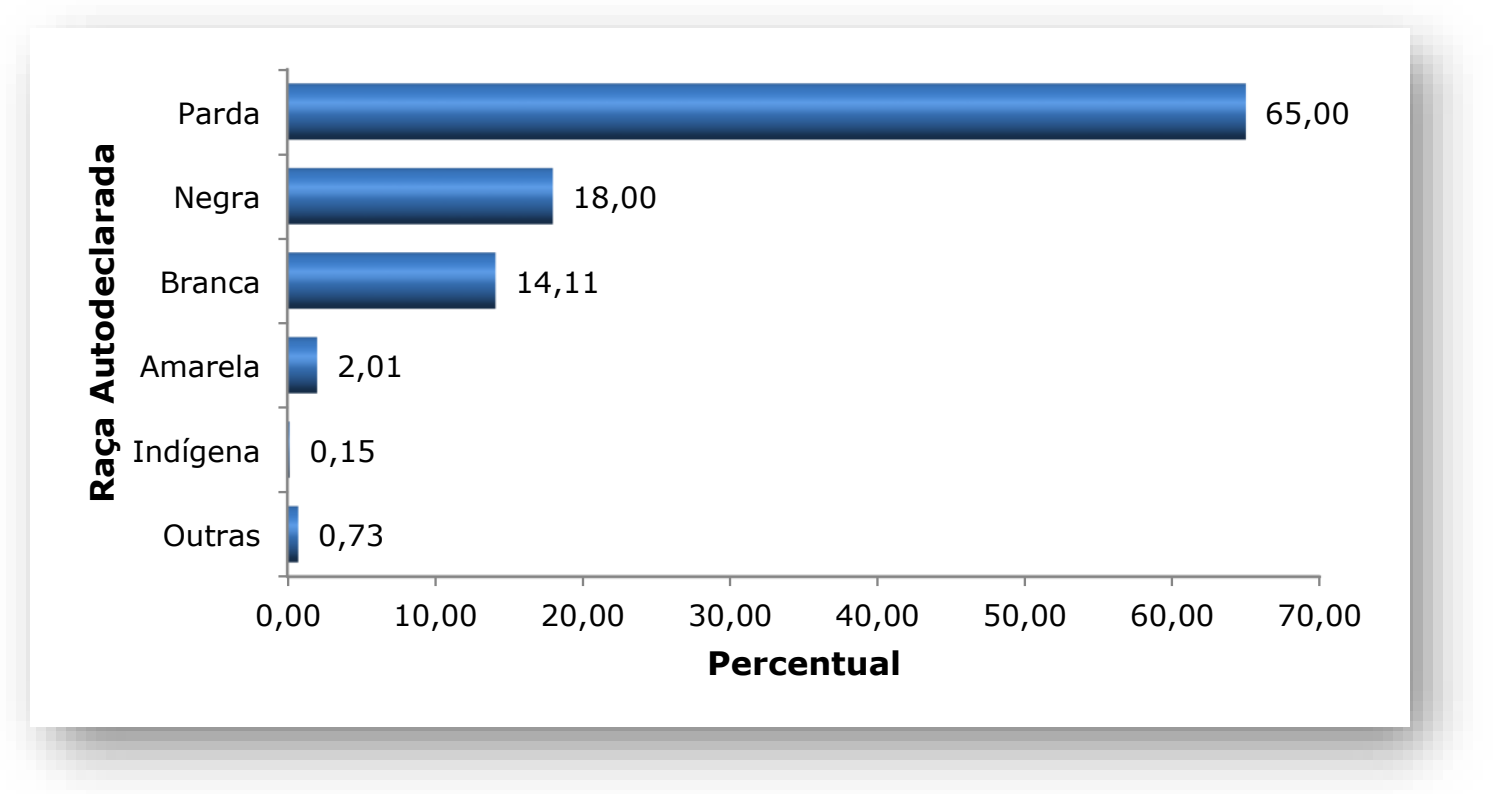

Fonte: SUSIPE, 2016.

O número de pardos e negros encarcerados no Estado do Pará está, inclusive, acima da média nacional apurada pelo DEPEN, correspondendo a 61\% no ano de 2014 (BRASIL, 2014). Isso é um forte indicativo de uma maior seletividade com base na raça nas políticas criminais do Estado do Pará, além de confirmar sua adequação aos moldes do Estado prisional. Considerando-se o nível de escolaridade dos presos, tem-se a clientela do sistema: 5,11\% de presos são analfabetos, $57,24 \%$ têm o nível fundamental incompleto, 10,33\%, o nível fundamental completo, 10,82\%, o nível médio incompleto, 7,40\%, o nível médio completo, 0,36\%, o nível superior incompleto, 0,36\%, o nível superior completo e 0,020\% já cursou alguma pós-graduação (SUSIPE, 2016). 
Gráfico 5 - Percentual de presos, conforme o critério escolaridade, no Estado do Pará, em maio de 2016

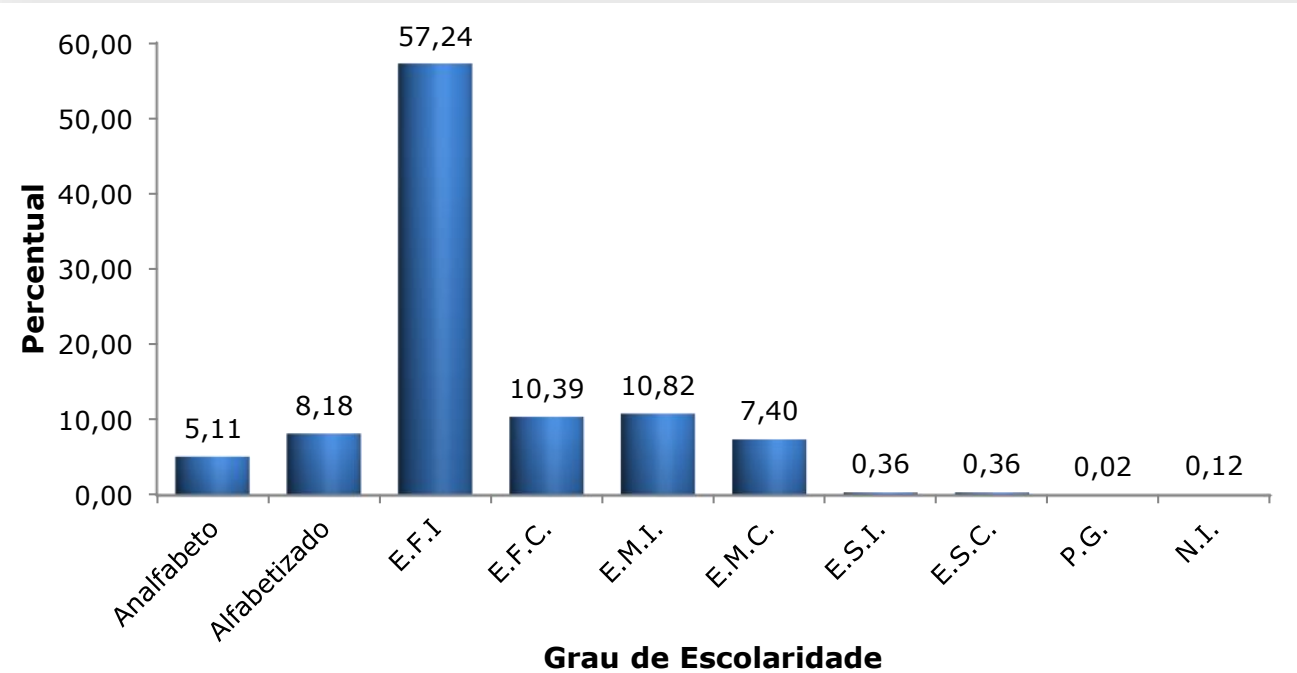

E.F.I. - Ensino Fundamental Incompleto E.F.C. - Ensino Fundamental Completo E.M.I. - Ensino Médio Incompleto E. M.C. - Ensino Médio Completo

\author{
E.S.I. - Ensino Superior Incompleto \\ E.S.C. - Ensino Superior Completo \\ P.G - Pós-Graduação \\ N.I. - Não Informado
}

Comparativamente, $86,57 \%$ dos encarcerados (classificados entre analfabetos e detentores de nível médio incompleto) compreendiam eventuais trabalhadores potencialmente aptos a disputar somente 35,39\% das vagas de trabalho formal abertas em 2013, no Estado do Pará, conforme dados estatísticos do anuário da Fundação Amazônica de Amparo a Estudos e Pesquisas do Pará (FAPESPA, 2015). Os outros 64,71\% das vagas de trabalho formal eram destinados a pessoas com nível médio completo em diante (FAPESPA, 2015).

Trata-se, portanto, de uma massa de cidadãos sujeita a um alto índice de exclusão do mercado formal de trabalho e, certamente, mais sujeita ao ingresso em atividades criminais como meio de sobrevivência. A essa massa de cidadãos, o Estado aplica a política criminal de encarceramento típica do Estado prisional (WACQUANT, 2015). Quanto ao critério de faixa etária, o cenário do Estado do Pará é semelhante ao nacional: a maior parte dos presos corresponde aos jovens em potencial idade laboral, 64,34\% deles têm idades de 18 a 29 anos (SUSIPE, 2016). E, seguindo a tendência nacional, constata-se também, que do total de 14.347 detentos no Pará, 45,6\% cumprem prisão provisória.

Em termos de custos ao Estado do Pará, verifica-se que, se, hipoteticamente, cada preso custasse o valor de $\mathrm{R} \$ 880,00$ ao mês ao sistema prisional paraense, o custo total mensal do encarceramento representaria o importe de $\mathrm{R} \$ 12.649 .120,00$. Esse valor, deve-se ressaltar, é 25,76\% maior do que os gastos dos benefícios previdenciários concedidos só no mês de janeiro de 2016 (que corresponderam a R\$ $9.839 .486,00)$.

Em linhas claras, constata-se que, no Estado do Pará, conforme uma tendência internacional e nacional já apontada, investe-se muito mais no encarceramento de uma parte selecionada da população do que em benefícios previdenciários, o que demonstra a plena adequação desse membro federativo a uma política ínsita no modelo de Estado prisional. E, pela constante evolução dos dados criminais, independentemente da gestão de governos, essa tendência parece ter-se perpetuado no Pará. Trata-se, conforme aponta Wacquant (2015), de mais uma medida de aparelhamento judiciário para controlar as classes perigosas. 


\section{CONSIDERAÇÕES FINAIS}

Com a mudança das dinâmicas de mercado e a transformação do capitalismo, assistiu-se a transformações nas relações de classes e nas normas trabalhistas, o que ocasionou maiores desigualdades sociais, exclusão e pobreza, tornando inviável a sustentação, pelas elites alinhadas aos Estados liberais, dos gastos típicos do Estado de bem-estar social.

Essas mudanças trouxeram novas dinâmicas familiares e comunitárias, suscitando fatores criminogênicos, aumentando significativamente o número de ilícitos e carecendo de respostas do poder estatal. O Estado prisional, descrito por Loïc Wacquant, é elucidativo dos processos instaurados a partir dos anos 1990, nos países neoliberais, nos quais houve redução da atuação assistencial e aumento da repressão à criminalidade.

Os mecanismos de endurecimento da legislação e de manutenção de uma vigilância e controle social dos pobres constituíram-se como política de Estado, apostando-se na repressão, ao contrário da construção da cidadania. Isso indica, de forma clara, que o sistema judiciário e as agências de segurança pública estão pouco voltados para a garantia do bem-estar e da cidadania consagrada constitucionalmente.

No entanto, perder a fé na mudança desse cenário não é uma alternativa plausível. Pois outras possibilidades podem ser adotadas para o controle social do crime, mas é necessário conhecer a face oculta do discurso político oficial da Lei e Ordem, ao sugerirem, após essa superação discursiva, uma reconstrução democrática que leve em conta a real complexidade social, e, sobretudo, identificar quem são os verdadeiros beneficiários e vítimas do tratamento criminal criado no Estado neoliberal.

\section{REFERÊNCIAS}

AZEVEDO, Rodrigo Ghiringhelli de. Criminalidade e justiça penal na América Latina. Sociologias, Porto Alegre, n. 13, p. 212-241, jan./jun. 2005.

BRASIL. Ministério da Justiça. Departamento Penitenciário Nacional. Levantamento Nacional de Informações Penitenciárias INFOPEN - junho de 2014. Brasília, DF, 2014.

. Ministério da Justiça. Ministério do Trabalho e Previdência Social. Boletim Estatístico da Previdência Social, Brasília, DF, v. 21, n. 1, jan. 2016.

DI PIETRO, Maria Sylvia Zanella. Discricionariedade administrativa na Constituição de 1988. 2. ed. São Paulo: Atlas, 2001.

FIGUEIREDO, Lucas. Ministério do Silêncio: a história do serviço secreto brasileiro de Washington Luís a Lula. Rio de Janeiro: Record, 2005.

. Lugar nenhum: militares e civis na ocultação dos documentos da ditadura. São Paulo: Companhia das Letras, 2015.

FUNDAÇÃO AMAZÔNICA DE AMPARO A ESTUDOS E PESQUISAS DO PARÁ (FAPESPA).

Anuário Estatístico do Pará 2015. Belém, 2015. Disponível em: <http:/ /www.fapespa.pa.gov.br /anuario_estatistico/social.html>. Acesso em: 28 nov. 2016.

INSTITUTO BRASILEIRO DE GEOGRAFIA E ESTATÍSTICA. Censo demográfico 2010: características da população e dos domicílios: resultados do universo. Rio de Janeiro, 2013a.

. Diretoria de Pesquisas. Coordenação de População e Indicadores Sociais. Projeção da população do Brasil e Unidades da Federação por sexo e idade para o período 2000-2030. Rio de Janeiro, 2013b.

Diretoria de Pesquisas. Coordenação de Trabalho e Rendimento. Pesquisa Nacional por Amostra de Domicílios Contínua 2015. Rio de Janeiro, 2015.

Projeções e estimativas da população do Brasil e das Unidades da Federação. Aplicativo de cálculo on line. Disponível em: <http://www.ibge.gov.br/apps/populacao/projecao/>. Acesso em: 1 nov. 2016. 
Projeções e estimativas da população do Brasil e das Unidades da Federação. Aplicativo de cálculo on line. Disponível em: <http://www.ibge.gov.br/apps/populacao/projecao/>. Acesso em: 1 nov. 2018.

KILDUFF, Fernanda. O controle da pobreza operado através do sistema penal. Revista Katálysis, Florianópolis, v. 13, n. 2, p. 240-249, jul./dez. 2010.

MONTEIRO, Felipe Mattos; CARDOSO, Gabriela Ribeiro. A seletividade do sistema prisional brasileiro e o perfil da população carcerária: um debate oportuno. Civitas: Revista de Ciências Sociais, Porto Alegre, v. 13, n. 1, p. 93-117, jan./abr. 2013.

MORAIS, José Luis Bolzan de; WERMUTH, Maiquel Ângelo Dezordi. A crise do Welfare State e a hipertrofia do Estado Penal. Sequência, Florianópolis, n. 66, p. 161-186, jul. 2013.

Estado punitivo e pós-modernidade: um estudo metateórico da contemporaneidade. Revista Crítica de Ciências Sociais, Coimbra, n. 98, p. 25-44, set. 2012.

RODRIGUES, Thiago. Política e drogas nas Américas. São Paulo: EDUC/FAPESP, 2004.

SALLA, Fernando; BALLESTEROS, Paula R. Democracia, direitos humanos e condições das pri-

sões na América do Sul. Paper for a Research Project to the Geneva Academy of International Humanitarian Law and Human Rights. São Paulo: Núcleo de Estudos da Violência, 2008.

SEIBEL, Erni J. O declínio do Welfare State e a emergência do estado prisional: Tempos de um novo puritanismo? Civitas: Revista de Ciências Sociais, Porto Alegre, v. 5. n. 1, p. 93-107, jan./jun. 2005.

SILVA, José Adaumir Arruda da. A privatização de presídios: uma ressocialização perversa. (In)compatibilidade com o Estado Democrático de Direito. Rio de Janeiro: Revan, 2016.

SOUZA, Robson Sávio Reis. Quem comanda a segurança pública no Brasil? Atores, crenças e coalizões que dominam a política nacional de segurança pública. Belo Horizonte: Letramento, 2015.

SUPERINTENDÊNCIA DO SISTEMA PENITENCIÁRIO DO ESTADO DO PARÁ. A SUSIPE em números - 2016. Belém, 2016.

WACQUANT, Loïc. Punir os pobres: a nova gestão da miséria nos Estados Unidos [A onda punitiva]. 3. ed. Rio de Janeiro: Revan, 2015. (Coleção Pensamento Criminológico, n. 6). 